\title{
Value of total thyroidectomy for Graves' disease in eliminating the risk of recurrence and malignancy: retrospective database analysis of 574 Saudi Arabian patients in 10 years with 2 years follow up
}

\author{
Bader Hamza Shirah ${ }^{1}$, Hamza Assad Shirah ${ }^{2}$
}

\author{
${ }^{1}$ King Abdullah International Medical Research Center / King Saud bin Abdulaziz University for Health Sciences, \\ Jeddah, Saudi Arabia \\ ${ }^{2}$ Department of General Surgery, Al Ansar General Hospital, Medina, Saudi Arabia
}

Received: 13 October 2015

Accepted: 05 December 2015

\author{
*Correspondence: \\ Dr. Bader Hamza Shirah, \\ E-mail: shirah007@ksau-hs.edu.sa
}

Copyright: () the author(s), publisher and licensee Medip Academy. This is an open-access article distributed under the terms of the Creative Commons Attribution Non-Commercial License, which permits unrestricted non-commercial use, distribution, and reproduction in any medium, provided the original work is properly cited.

\begin{abstract}
Background: Graves' disease is an autoimmune disease that affects the thyroid gland and frequently results in hyperthyroidism and an enlarged thyroid. Treatment of Graves' disease includes antithyroid drugs, radioiodine (radioactive iodine I-131), and thyroidectomy, either total, or subtotal excision. In this paper, we aim to analyse the outcome of thyroidectomy performed on patients affected by Graves' disease in Medina - Saudi Arabia, and evaluate if thyroidectomy should be considered the first treatment option for all patients with Graves' disease.

Methods: A retrospective database analysis of the surgical treatment outcome of 574 Saudi Arabian patients who were affected with Graves' disease between January 2003 and December 2012 was done. The computerized database medical records were reviewed and analysed for preoperative, intraoperative, and postoperative factors.

Results: $194(33.8 \%)$ patients were males, and $380(66.2 \%)$ were females. The average age of patients was $44 \pm 2$ years. $154(26.8 \%)$ had subtotal thyroidectomy, and $420(73.2 \%)$ had total thyroidectomy performed. There was $(0 \%)$ recurrent laryngeal nerve injury, and $(0 \%)$ intraoperative complication were recorded. With a follow up time of 2 years, $7(1.22 \%)$ patients developed recurrent disease (all in subtotal thyroidectomy group). There were no recurrences in the total thyroidectomy patients, and $11(1.9 \%)$ patients were found in histopathology to have papillary thyroid cancer (all in total thyroidectomy group).

Conclusions: We conclude that total thyroidectomy is a safe and effective treatment modality for Graves' disease that offers rapid and long-lasting results, in addition to eliminating the risk of recurrence and malignancy. It should be offered to all confirmed Graves' disease patients during counselling.
\end{abstract}

Keywords: Thyroidectomy, Grave's disease, Hyperthyroidism, Hypocalemia, Recurrent laryngeal nerve injury, Recurrence

\section{INTRODUCTION}

Graves' disease, also known as toxic diffuse goiter, is an autoimmune disease of the thyroid which results in hyperthyroidism and an enlarged thyroid. Signs and symptoms of hyperthyroidism may include irritability, muscle weakness, sleeping problems and a fast heartbeat, poor tolerance of heat, diarrhea, and weight loss. Other symptoms may include thickening of the skin on the shins, known as pretibial myxedema, and eye problems such as bulging, a condition known as Graves' ophthalmopathy. About $25 \%$ to $80 \%$ of people develop eye problems. ${ }^{1}$

The prevalence of Graves' disease is $0.5 \%$ of the population, the incidence is higher in women (around 5 $10: 1$ ), and is the underlying etiology for $50-80 \%$ of cases of hyperthyroidism. Often it starts between the ages of forty and sixty, clearly in any age, although $20-40$ years old more often. Graves' disease is not only 
associated with a decrease in quality of life, but if left untreated, it can lead to cardiovascular disease, including atrial fibrillation, cardiomyopathy and congestive heart failure. Severe thyrotoxicosis is associated with a mortality of $20-50 \% .^{2}$

The disorder results from an antibody, called thyroid stimulating immunoglobulin (TSI), that has a similar effect to thyroid stimulating hormone (TSH). These antibodies cause the thyroid gland to produce excess thyroid hormone. The diagnosis may be suspected based on symptoms with blood tests and radioiodine uptake used to confirm the disease. Typically blood tests show a raised $\mathrm{T} 3$ and $\mathrm{T} 4$, low $\mathrm{TSH}$, increased radioiodine uptake in all areas of the thyroid, and TSI antibodies. In Graves' disease, thyroid tissue typically become hypoechoic because of reduction in colloid content, increase in thyroid vascularity and lymphocytic infiltration. In colour flow doppler there is a distinct pattern characterized by markedly increased signals, inferior thyroid artery velocities more than $40 \mathrm{~cm} / \mathrm{s}$. This pattern, in conjunction with a hypoechoic pattern allows distinction from Hashimoto's thyroiditis. ${ }^{3}$

Treatment of Graves' disease includes antithyroid drugs which reduce the production of thyroid hormone; the main antithyroid drugs are carbimazole, methimazole, and propylthiouracil/PTU. These drugs block the binding of iodine and coupling of iodotyrosines. The most dangerous side effect is agranulocytosis (1/250, more in PTU). Others include granulocytopenia (dose-dependent, which improves on cessation of the drug) and aplastic anaemia. Treatment with antithyroid medications must be given for six months to two years to be effective. Even then, upon cessation of the drugs, the hyperthyroid state may recur. ${ }^{4}$

Another option is radioiodine (radioactive iodine I-131); Indications for radioiodine are: failed medical therapy or surgery and where medical or surgical therapy is contraindicated. Hypothyroidism may be a complication of this therapy, but may be treated with thyroid hormones if it appears. The rationale for radioactive iodine is that it accumulates in the thyroid and irradiates the gland with its beta and gamma radiations, about $90 \%$ of the total radiation being emitted by the beta (electron) particles. The most common method of iodine-131 treatment is to administer a specified amount in microcuries per gram of thyroid gland based on palpation or radiodiagnostic imaging of the gland over 24 hours. ${ }^{5}$

The third option is thyroidectomy, either total, near total, or subtotal excision, all had been described in the literature, and as operating on a frankly hyperthyroid patient is dangerous, prior to thyroidectomy preoperative treatment with antithyroid drugs is given to render the patient "euthyroid". 6

The treatment modalities used vary in different parts of the world. Therapy with radioiodine is the most common treatment in the United States, while antithyroid drugs and/or thyroidectomy are used more often in Europe, Japan, and most of the rest of the world. ${ }^{2}$

Recent literature supports the use of surgery as an initial treatment option for Graves' disease. ${ }^{7}$ Research shows that thyroidectomy has a lower recurrence rate than radioiodine or antithyroid drugs. ${ }^{8}$ In addition; some patients with significant opthalmopathy or goiter may be best served with surgical treatment. ${ }^{6}$ Surgery provides rapid control of hyperthyroidism and a high cure rate. Two surgical options are available: subtotal thyroid resection aiming to preserve thyroid function, and total thyroidectomy to ablate thyroid function eliminating the risk of recurrent toxicity and reoperation.

In our paper, we aim to analyse the outcome of thyroidectomy performed on patients affected by Graves' disease in Medina - Saudi Arabia, and evaluate if thyroidectomy should be considered the first treatment option for all patients with Graves' disease.

\section{METHODS}

A retrospective database analysis of the surgical treatment outcome of 574 Saudi Arabian patients affected with Graves' disease between January 2003 and December 2012 was done. All patients were referred to the general surgery outpatient clinic in two public health general hospitals in Medina, Saudi Arabia. The preoperative work up, selection of patients, surgical procedures, and follow up were carried out by the same surgical team.

All patients had the same preoperative work up (complete blood count- coagulation profile- blood chemistry- chest $\mathrm{x}$-ray- electrocardiogram- thyroid hormone levels- neck doppler ultrasound- thyroid function test- fine needle aspiration). The procedure and postoperative care were carefully discussed with the patients; all patients were admitted to the surgical floor one day before surgery, and discharged on the fourth postoperative day.

The procedure was done under general anaesthesia, supine position; a conventional thyroidectomy approach was done to all patients. Parathyroid auto-transplant was done to all patients. A drain was used in all patients and was removed when collecting less than $50 \mathrm{ml}$ per day. The neck incision was closed in cosmetic subcuticular pattern in all patients. All patients were given cefazolin prophylactic antibiotic, and all patients who had total thyroidectomy were started postoperatively on replacement thyroxin orally.

The computerized database medical records were reviewed and analyzed for preoperative factors such as age, sex, duration of the disease, thyroid function tests, use and duration of radioiodine or antithyroid drugs, and indication for surgery. 
The intraoperative factors included estimated blood loss, operative time, extent of excision (subtotal, and total), recurrent laryngeal nerve injury, parathyroid autotransplants, and complications.

Postoperative factors reviewed were drains, neck hematoma, serum calcium level, transient and permanent hypocalcaemia, neck wound infection, wound scar, pathology of specimen, and recurrence.

\section{RESULTS}

574 Saudi Arabian patients affected with Graves' disease were included, 194 (33.8\%) were males, and $380(66.2 \%)$ were females, ratio of $1: 1.96$.

At the same period, the overall total number of patients treated in our hospital for various diseases was 79364 patients, among them, 5827 were patients with different thyroid diseases. The incidence rate of Graves' disease in our hospital population was $0.72 \%$. The incidence rate of Graves' disease in our hospital thyroid patients was 9.9 $\%$. The average age of patients was $44 \pm 2$ years. Family history of thyroid disease (hypothyroidism, hyperthyroidism, thyroid cancer or disease) was recorded in $58(10.1 \%)$ patients. The range of the disease duration was $(4-7)$ years, $($ median $=5.5)$. The mean baseline preoperative TSH and free $\mathrm{T} 4$ values were $0.14 \pm 0.37$ $\mathrm{mU} / \mathrm{L}$ and $7.8 \pm 8.3 \mathrm{mcg} / \mathrm{dL}$, respectively.

All patients $(100 \%)$, received preoperative anti-thyroid medication, $422(73.5 \%)$ had Carbimazole, and 152 (26.5\%) Propylthiouracil. Beta blockers were used in all patients $(100 \%)$. While $83(14.5 \%)$ patients had radioiodine therapy, $290(50.5 \%)$ patients refused the option, and $201(35 \%)$ patients were not offered the treatment.

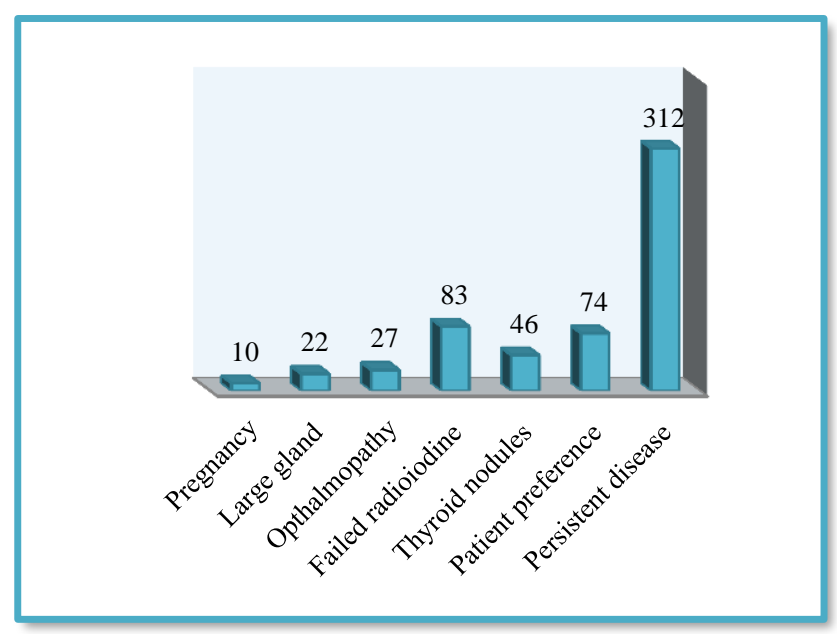

Figure 1: The reason for preferring thyroid surgery in 574 Graves' disease patients.

The most common reason for preferring thyroid surgery was persistent disease despite medical therapy in 312
$(54.4 \%)$ patients. While patient preference was reported by $74(16.7 \%)$ patients. Evidence of thyroid nodules in 46 $(8 \%)$ patients, failed radioiodine treatment in $83(14.5 \%)$, large gland in $22(3.8 \%)$, opthalmopathy in $27(4.7 \%)$, and pregnancy in $10(1.7 \%)$. persistent disease despite medical therapy of Graves' disease was found to be statistically significant reason for surgery $(p<0.05)$.

Regarding operative data, 154 (26.8\%) had subtotal thyroidectomy, and $420(73.2 \%)$ had total thyroidectomy performed. The average operative time was $125 \pm 5$ minutes, and the mean estimated blood loss was $62 \pm 17$ $\mathrm{mL}$. There was $(0 \%)$ recurrent laryngeal nerve injury, parathyroid auto-transplant was performed in all patients $(100 \%)$, and $(0 \%)$ intraoperative complications were recorded.

Postoperative analysis showed that in 361 (62.9\%) patients drains were removed on the second postoperative day, and in $213(37.1 \%)$ on the third postoperative day. The mean postoperative calcium was $8.5 \pm 0.1 \mathrm{mg} / \mathrm{dL}$. Though, $83(14.5 \%)$ patients experienced transient symptomatic hypocalcaemia. There was no recurrent laryngeal nerve injuries recorded. 17 (2.96\%) patients had neck wound infection, $6(1.05 \%)$ patients developed hypertrophic neck wound scar.

$563(98.1 \%)$ patients had typical histopathological features of Graves' disease on final histopathology, and $11(1.9 \%)$ patients were found in histopathology specimens to have papillary thyroid cancer (all from the total thyroidectomy group).

Table 1: Postoperative analysis of thyroid surgery outcome in Graves' disease patients.

\begin{tabular}{|lll|}
\hline Factors & \multicolumn{1}{c|}{$\begin{array}{c}\text { Subtotal } \\
\text { thyroidectomy }\end{array}$} & $\begin{array}{c}\text { Total } \\
\text { thyroidectomy }\end{array}$ \\
\hline Patients No. & $154(26.8 \%)$ & $420(73.2 \%)$ \\
\hline $\begin{array}{l}\text { Total gland weight, } \\
\text { mean, grams }\end{array}$ & 68 & 52 \\
\hline $\begin{array}{l}\text { Remnant gland weight, } \\
\text { mean, grams }\end{array}$ & 6 & 0 \\
\hline $\begin{array}{l}\text { Resected gland weight, } \\
\text { mean, grams }\end{array}$ & 62 & 52 \\
\hline $\begin{array}{l}\text { Proportion of gland } \\
\text { resected (\%) }\end{array}$ & 91 & 100 \\
\hline $\begin{array}{l}\text { Transient symptomatic } \\
\text { hypocalcaemia, patients } \\
\text { No. }\end{array}$ & 19 & 64 \\
\hline $\begin{array}{l}\text { Recurrent laryngeal } \\
\text { nerve injuries, patients } \\
\text { No. }\end{array}$ & 0 & 0 \\
\hline $\begin{array}{l}\text { Neck wound infection, } \\
\text { patients No. }\end{array}$ & 6 & 11 \\
\hline $\begin{array}{l}\text { Hypertrophic neck } \\
\text { wound scar }\end{array}$ & 2 & 4 \\
\hline Papillary thyroid cancer & 0 & $7(1.22 \%)$ \\
\hline Recurrence & 0 \\
\hline
\end{tabular}


There was no difference in overall complication rates between patients based on surgical procedure (subtotal and total thyroidectomy). Mortality rate was $(0 \%)$.

With a follow up time of 2 years, 7 (1.22\%) patients developed recurrent disease.

All recurrences occurred in patients who underwent a subtotal thyroidectomy, and all 7 patients were successfully treated with postoperative radioiodine. There were no recurrences in the total thyroidectomy patients. Recurrence of Graves' disease was found to be statistically significant with subtotal thyroidectomy surgery $(\mathrm{p}<0.05)$.

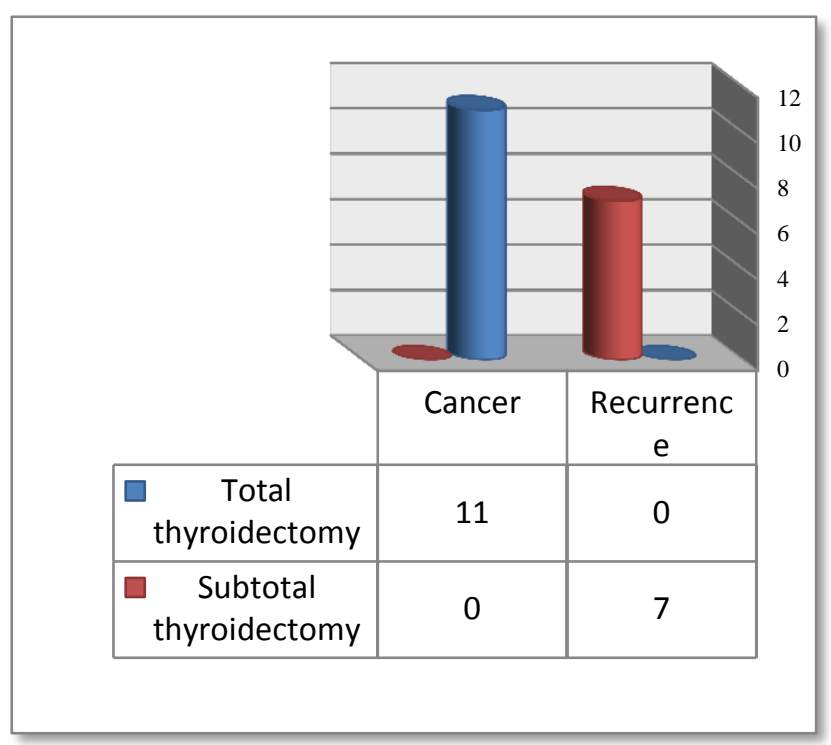

Figure 2: Comparison for recurrence and cancer occurrence in thyroid surgery in 574 Graves' disease patients.

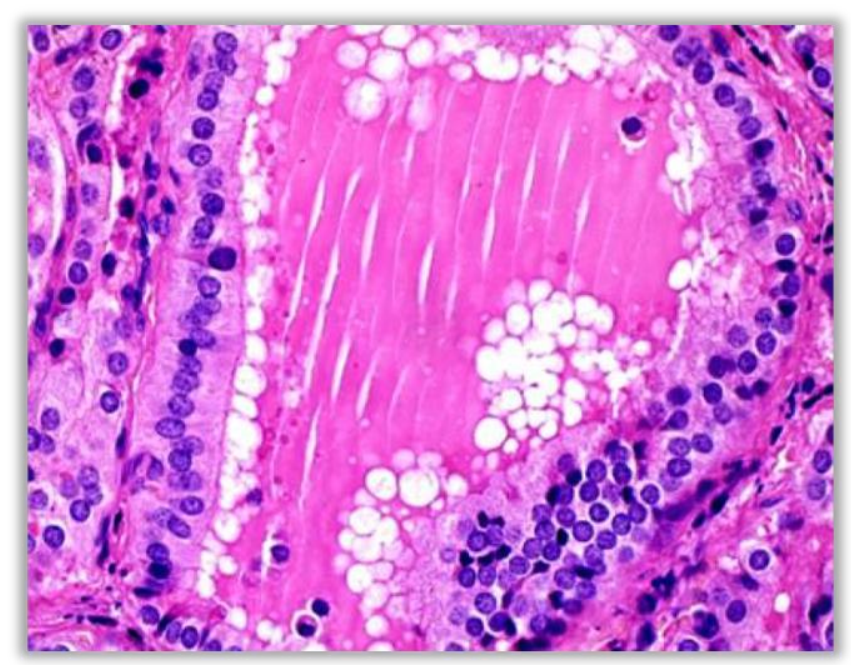

Figure 3: High power section of Graves' disease thyroid follicle showing scalloping caused by reabsorption of stored colloid secondary to activation of the surface TSH receptors by auto-antibodies.

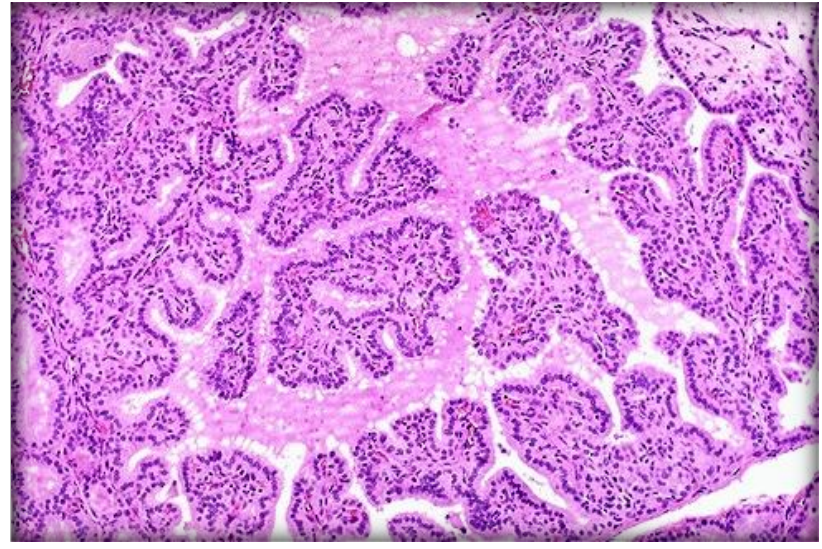

Figure 4: Low power section of Graves' disease showing a diffusely enlarged thyroid gland and prominent infoldings of the hyperplastic follicular epithelium.

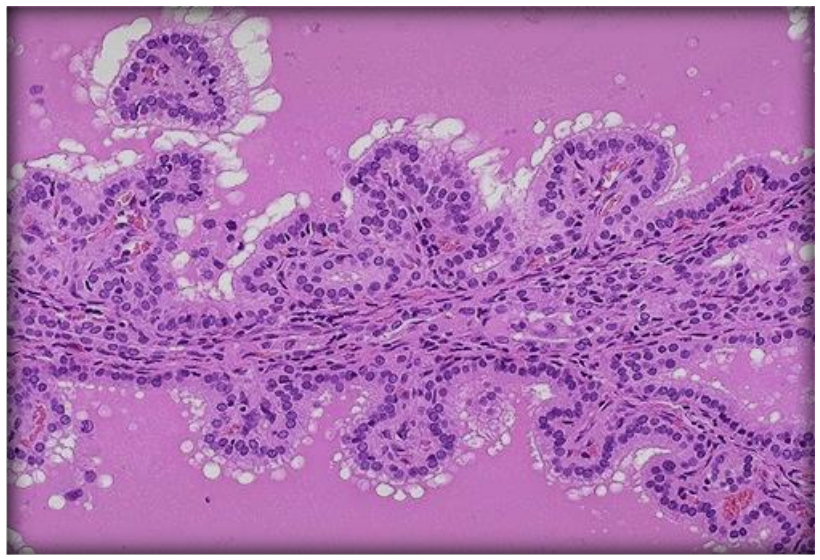

Figure 5: High power section showing tall columnar thyroid epithelium with Graves' disease lines the hyperplastic infoldings into the colloid with clear vacuoles in the colloid next to the epithelium where the increased activity of the epithelium to produce increased thyroid hormone has led to scalloping out of the colloid in the follicle.

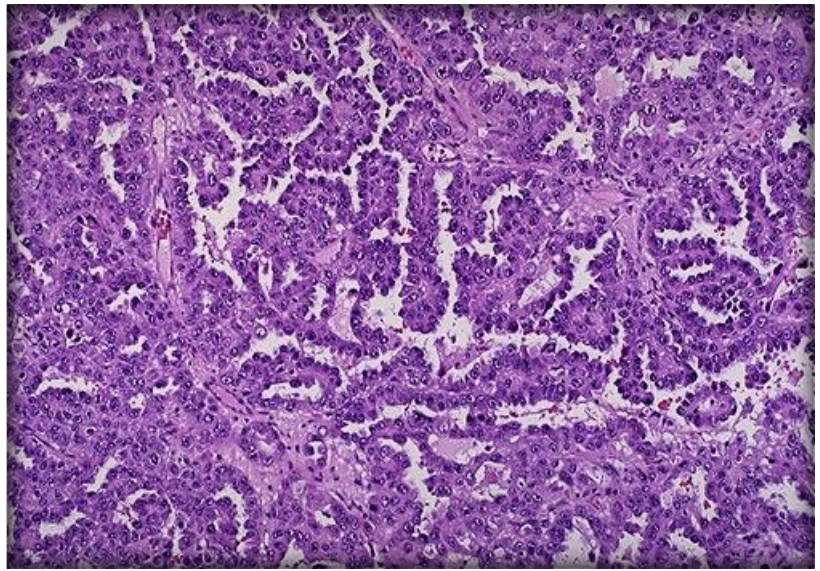

Figure 6: High power section of papillary carcinoma of the thyroid showing thin Fibrovascular cores, and papillary pattern. 


\section{DISCUSSION}

The management guidelines of the American Thyroid Association and American Association of Clinical Endocrinologists for Graves' disease include any of the following modalities: 131 I therapy, antithyroid medication, or thyroidectomy. No in-depth analysis has been performed comparing the treatment options, even though a single treatment option seems to be universally accepted. A systematic review of the literature was performed to examine contemporary literature between 2001 and 2011 evaluating the management options of Graves' disease. On the basis of the outcomes analyzed, surgery appears to be the most successful in the management of Graves' disease, with total thyroidectomy being the preferred surgical option. ${ }^{5}$ Our study results showed that thyroidectomy, particularly total thyroidectomy, is a safe and effective option for a definitive treatment of Graves' disease.

It has been shown that the complication rates of permanent recurrent laryngeal nerve palsy (0-1.3\%) and permanent hypoparathyroidism $(1 \%)$ following subtotal thyroidectomy are similar to those following total thyroidectomy ${ }^{13}$. In addition, the disadvantages of subtotal thyroidectomy to treat Graves' disease are that the procedure does not prevent persistent or recurrent disease in up to $20 \%$ of patients; it does not stop the process of the disease and, as a result, it cannot stop the progress of ophthalmopathy; and it does not address hypothyroidism in up to $70 \%$ of patients. ${ }^{14}$

In contrast, total thyroidectomy eliminates all abnormal tissue in the neck and lowers recurrence rates for Graves' disease. Furthermore, after total thyroidectomy, hormone replacement with L-thyroxine is relatively easy and can be achieved by monitoring the thyroid hormone serum levels. As a result, total thyroidectomy is currently regarded as the surgical procedure of choice to treat Graves' disease. $^{6}$

Complications of thyroidectomy include transient hypocalemia, permanent.

Hypocalemia and recurrent laryngeal nerve injury. Many physicians fear that the complication rates are higher in patients with Graves' disease due to the increase.

Vascularity and inflammation found in these glands. Several studies reported rates of $6-20 \%$ for transient hypocalemia and $0-3 \%$ for permanent hypocalemia, and $0 \%$ for recurrent laryngeal nerve, damage, suggesting the thyroidectomy in patients with Graves' is safe, and is associated with a very low risk of complications. ${ }^{2,6,9}$ Our complication rates were $14.5 \%$ for transient hypocalemia and $0 \%$ for permanent.

Hypocalemia and recurrent laryngeal nerve injury, which is consistent with the accepted standards.
Injury, devascularization, and unintentional excision of the parathyroids have all been cited as the causes of postoperative hypocalcemia. Although other specific factors have been studied, the cause of postoperative hypocalcemia remains to be multifactorial. Although hypocalcemia reverses spontaneously in most patients, it can remain permanent when caused by an irreversible injury to the parathyroid glands ${ }^{15}$. Transient hypocalemia was recorded as early as the first postoperative day in our patients, and was treated by intravenous or oral calcium and vitamin D3 supplementation. Patients were discharged with oral calcium and vitamin D3 prescription. The routine administration of calcitriol and/or calcium to all patients either pre- or postoperatively are strategies that have been advocated. ${ }^{16}$

Our results suggest that the majority of patients, (54.4\%), selected thyroidectomy as a definitive treatment for Graves' disease after the failure of antithyroid drugs and/ or radioiodine treatment. Although antithyroid drugs and radioiodine can be effective treatment options, they are associated with much higher recurrence rates and are not without their own complications. On the other hand, treatment by thyroidectomy is rapid, stops hyperthyroidism, provides tissue for histological examination and produces an immediate cure. Further, there is absolute titration of thyroid hormone replacement. It avoids potential complications associated with antithyroid drugs (e.g. agranulocytosis and fulminant hepatitis). Unlike radiation therapy it does not carry increased risk of benign thyroid tumours and malignant transformations in young adults. Research has suggested that surgery might be a better treatment option for patients with Graves' opthalmopathy, as opthalmopathy has been reported to improve in $71-74 \%$ of Graves' patients after thyroid surgery. ${ }^{10}$

Thyroid cancer is an established reported finding in patients surgically treated for Graves' disease. The incidence of thyroid cancer has been shown to be as high as $15-20 \%$. $^{11}$ In our study, on final histopathology, 11 $(1.9 \%)$ patients were found to have papillary thyroid cancer. Fortunately, all 11 patients had total thyroidectomy, thus eliminating the hidden malignant lesion, and they were all scheduled for follow up to check for lymph nodes metastasis.

Thyroid nodules are frequently found in patients with Graves' disease, though the frequency varies depending on the method used. The prevalence of palpable thyroid nodule is 3-fold higher compared to the general population. In epidemiological studies, higher thyroid nodule prevalence is found when thyroid ultrasonography is used for evaluation of thyroid morphology. In addition, thyroid nodule develops in approximately half of the patients with Graves' disease during the follow-up. There is an increased risk of thyroid cancer in presence of these nodules. While the rate of malignancy is approximately $5 \%$ in palpable thyroid nodules in the general population, it varies between $2.3 \%$ and $45.8 \%$ in patients with 
Graves' disease. Moreover, there has been much controversy regarding biological behaviour of cancers in Graves' patients. While some authors have reported that thyroid cancers have a more aggressive course, some others have reported the contrary ${ }^{16}$. In our series, evidence of thyroid nodules was found in $46(8 \%)$ patients, in which $11(1.9 \%)$ patients of them were found to have papillary thyroid cancer in the final histopathology.

In our study, all recurrences were observed in patients who underwent a subtotal thyroidectomy, and none in patients who underwent a total thyroidectomy. In addition, the complication rates were low in all 2 methods. Although total thyroidectomy renders patients permanently hypothyroid, this is anticipated and can be easily treated with thyroid hormone replacement immediately postoperatively in order to avoid hypothyroidism. Most other treatment options also cause patients to become hypothyroid, although this is less predictable and patients are more likely to become symptomatic before it is recognized and appropriate replacement is initiated. Thus, we believe total thyroidectomy is the safest option to treat Graves' disease.

Ralls and associates first used color Doppler sonography in 1988 for the diagnosis of Graves' disease. ${ }^{17}$ They used the term "inferno" to refer to the pulsatile flow pattern in Graves' disease, which was obvious in all 16 patients with Graves' disease in their study, as compared to controls. Arslan and associates were able to demonstrate the peculiar diffuse hypervascularity in all 23 Graves' disease patients of their study. ${ }^{18}$ Cappelli et al recently published a large prospective study ${ }^{19}$ on hyperthyroid patients ( $n=1470$, with 426 with Graves' disease), reporting excellent sensitivity and specificity of ultrasound in Graves' disease (by vascular Doppler pattern). The ultrasound Doppler had 95\% sensitivity and 95\% specificity, as compared to those of RAI scan (97\% and $99 \%$, respectively).

More recently, Kumar et $\mathrm{al}^{20}$ reported the excellent diagnostic accuracy of peak systolic velocity of the inferior thyroid artery as measured by ultrasound Doppler in hyperthyroidism. In a study of 65 patients with hyperthyroidism (Graves' disease versus thyroiditis), this particular technique had a sensitivity of $96 \%$ and specificity of $95 \%$, with a peak systolic velocity of 40 $\mathrm{cm} / \mathrm{sec}$ as a cut-point diagnostic value. This technique has thus added a quantitative tool to supplement the qualitative tool of tissue vascularity; the two tools can be very helpful in the diagnosis of Graves' disease.

Figure 7 (a-g) shows color Doppler ultrasound of the thyroid gland showing enlarged, bulky and heterogeneous features. The right lobe measures $6.1 \times 2.3 \times 2.4 \mathrm{~cm}$. The left lobe measures $5.5 \times 2 \mathrm{~cm} \times 1.8 \mathrm{~cm}$. The isthmus is also bulky and measuring $1.3 \mathrm{~cm}$. There is diffuse increased in vascularity of the whole thyroid gland (inferno). Bilateral cervical lymph nodes are noted.
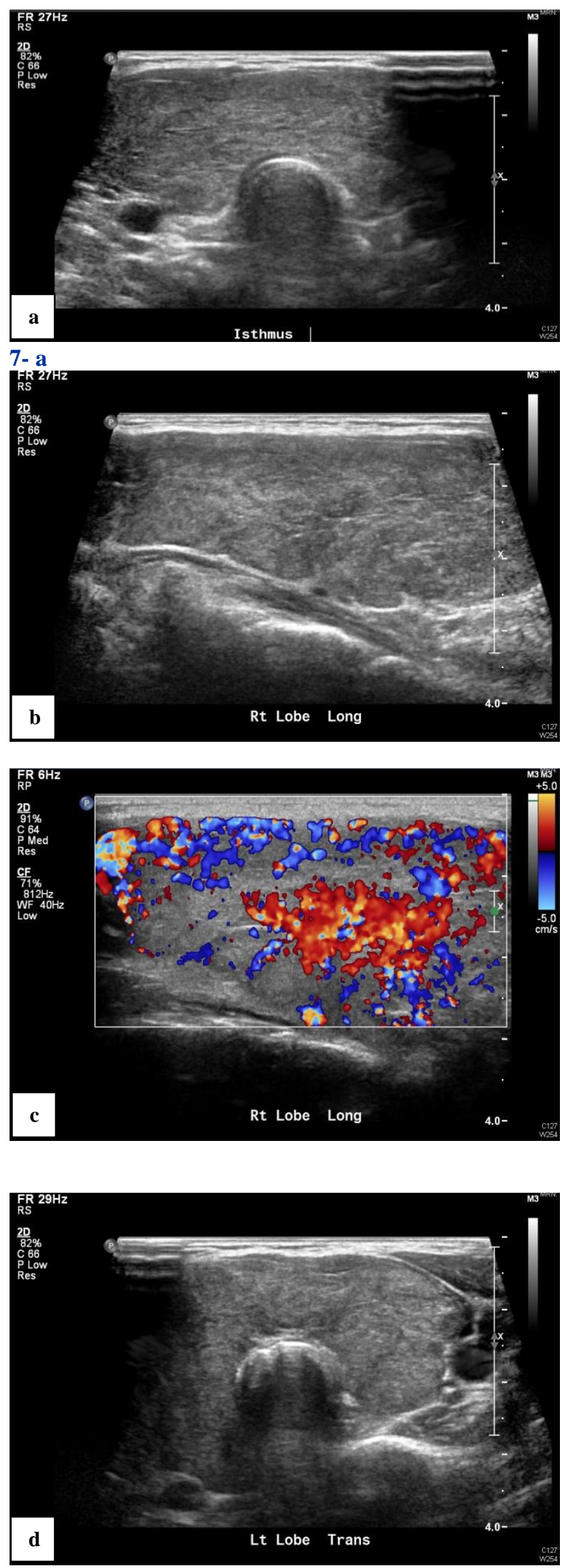

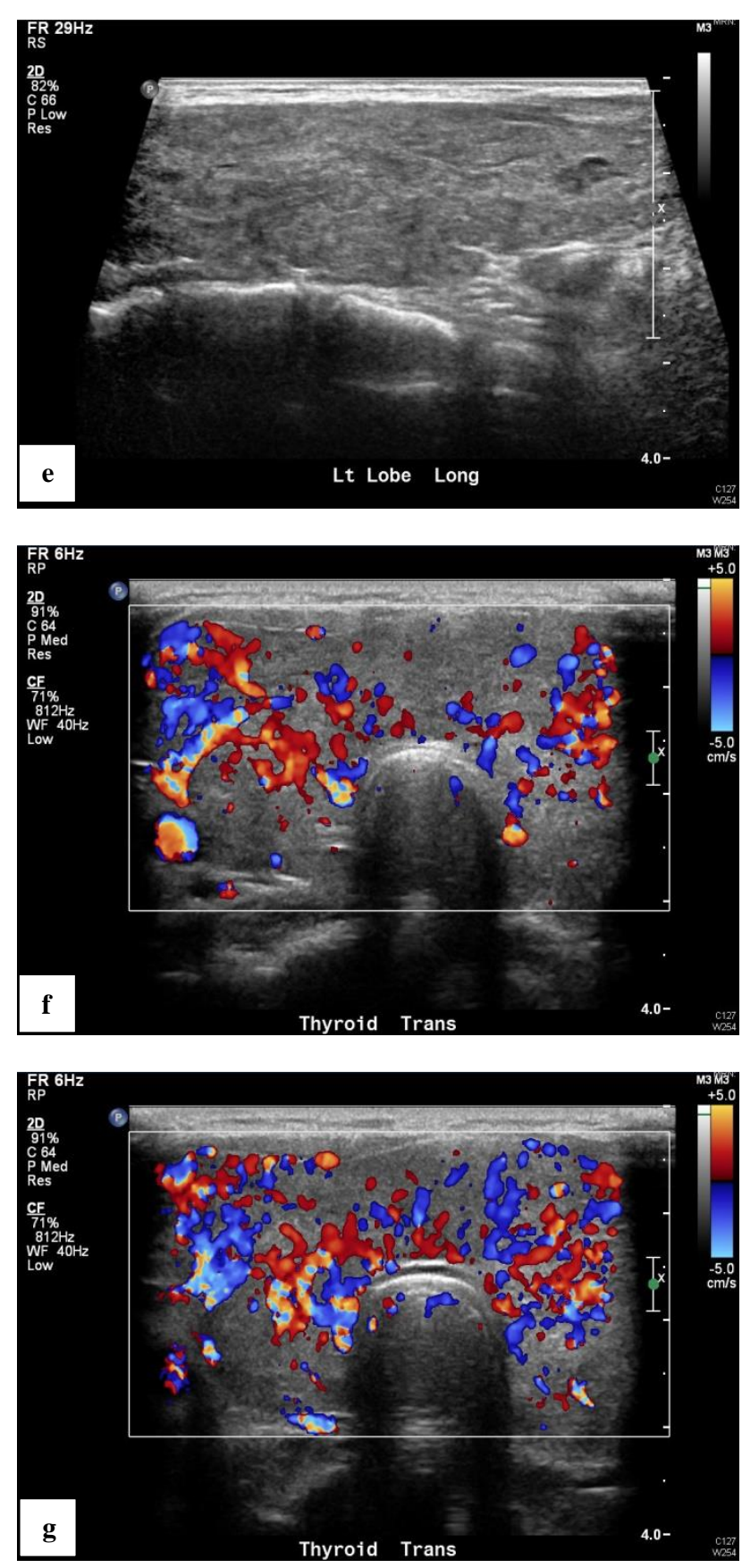

Figure 7 (a-g): Color Doppler sonography of Graves' disease patient from the study population showing the inferno.

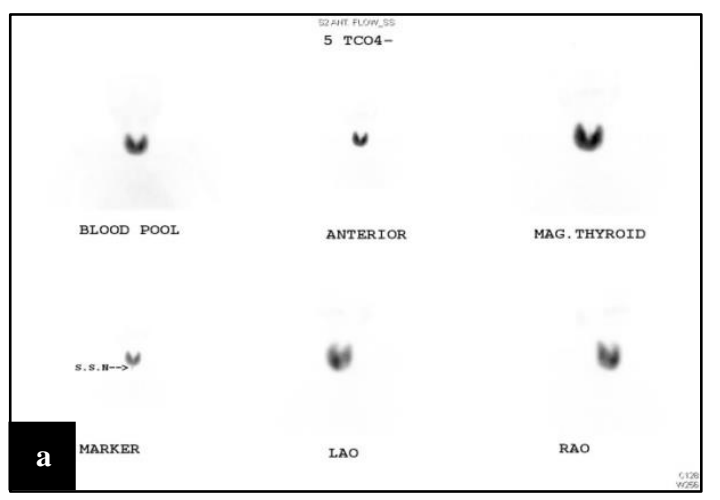

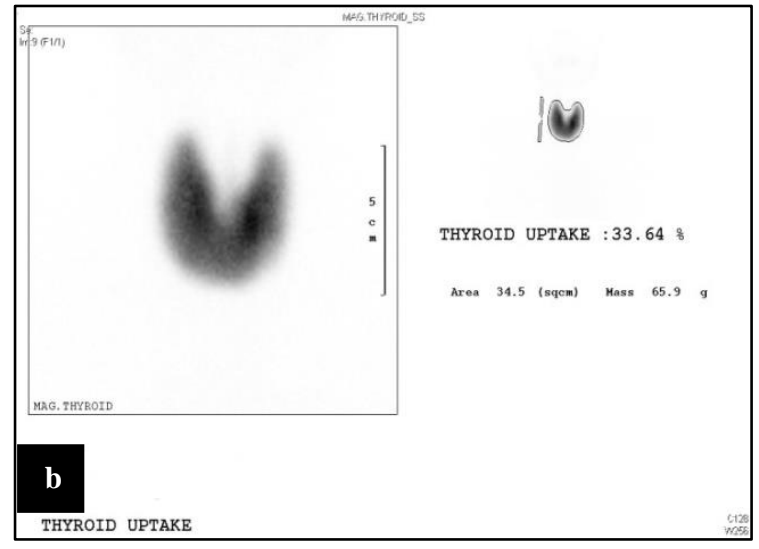

Figure 8 (a \& b): Thyroid nuclear scan of Graves' disease where the thyroid gland appeared moderateto-severely enlarged with increased flow and uptake, which however, appeared homogeneous. The estimated thyroid mass was around $60 \mathrm{gm}$ and the calculated thyroid uptake was significantly increased at around $33 \%$ (normal 0.4 to $1.5 \%$ ).

Figure 8 (a \& b) shows Thyroid nuclear scan of Graves' disease patient from the study population showing increased uptake.

\section{CONCLUSIONS}

We conclude that total thyroidectomy is a safe and effective treatment modality for Graves' disease that offers rapid and long-lasting results, in addition to eliminating the risk of recurrence and malignancy. It should be offered to all confirmed Graves' disease patients during counselling.

Funding: No funding sources

Conflict of interest: None declared

Ethical approval: The study was approved by the Institutional Ethics Committee

\section{REFERENCES}

1. Brent, Gregory A. Clinical practice. Graves' disease. The New England Journal of Medicine. 2008;358(24):2594-605.

2. Boostrom S, Richards ML. Total thyroidectomy is the preferred treatment for patients with Graves' disease and a thyroid nodule. Otolaryngol Head Neck Surg. 2007;136(2):278-81.

3. Menconi F, Marcocci C, Marinò M. Diagnosis and classification of Graves' disease. Autoimmunity reviews. 2014;13(4-5):398-402.

4. Homsanit M, Sriussadaporn S, Vannasaeng S, Peerapatdit T, Nitiyanant W, Vichayanrat A. Efficacy of single daily dosage of methimazole vs. propylthiouracil in the induction of euthyroidism. Clin. Endocrinol. (Oxf). 2001;54(3):385-90.

5. Genovese BM, Noureldine SI, Gleeson EM, Tufano RP, Kandil E. What is the best definitive treatment for Graves' disease? A systematic review of the 
existing literature. Annals of Surgical Oncology (review). 2013;20(2):660-7.

6. Lal G, Ituarte P, Kebebew E, Siperstein A, Duh QY, Clark $\mathrm{OH}$. Should total thyroidectomy become the preferred procedure for surgical management of Graves' Disease?. Thyroid. 2005;15(6):569-74.

7. Alsanea O, Clark OH. Treatment of Graves' disease: the advantages of surgery. Endocrinol Metab Clin North Am. 2000;29(2):321-37.

8. Leech NJ, Dayan CM. Controversies in the management of Graves' disease. Clin Endocrinol (Oxf). 1998;49(3):273-80.

9. Acharyya BN, Fried MP. Assessment of the morbidity and complications of total thyroidectomy. Arch Otolaryngol Head Neck Surg. 2002;128(4):389-92.

10. Jortso E, Lennquist S, Lundstrom B, Smeds S. The influence of remnant size, antithyroid antibodies, thyroid morphology and lymphocyte infiltration on thyroid function after subtotal resection for hyperthyroidism. World J Surg. 1987;11:365-71.

11. Behar R, Arganini M, Wu TC, McCormick M, Straus FH 2nd, DeGroot LJ et al. Graves' disease and thyroid cancer. Surgery. 1986;100(6):1121-7.

12. Schussler-Fiorenza CM, Bruns CM, Chen H: The surgical management of Graves' disease. J Surg Res. 2006;133(2):207-14.

13. Pattou F, Combemale F, Fabre S. Hypocalcaemia following thyroid surgery incidence and prediction of outcome. World J Surg. 1998;22:718-24.

14. Ku CF, Lo CY, Chan WF. Total thyroidectomy replaces subtotal thyroidectomy as the preferred surgical treatment for Graves disease. ANZ J Surg. 2005;75:528-31.

15. Thompson NW, Reeve T. Complications of thyroid surgery: How to avoid them, how to manage them, and observations on their possible effect on the whole patient. World J Surg. 2000;24:971-5.

16. Kraimps JL, Bouin-Pineau MH, Mathonnet M, De Calan L, Ronceray J, Visset J. Multicenter study of thyroid nodules in patients with Graves's disease. $\mathrm{Br}$ J Surg. 2000;87:1111-3.

17. Ralls PW, Mayekawa DS, Lee KP, Colletti PM, Fadin DR, Boswell WD et al. Color-flow Doppler sonography in GD: 'thyroid inferno' Am J Roentgenol. 1988;150:781-4.

18. Arslan H, Unal O, Algün E, Harma M, Sakarya ME. Power Doppler sonography in the diagnosis of Graves> disease. Eur J Ultrasound. 2000;11:117-22.

19. Cappelli C, Pirola I, De Martino E, Agosti B, Delbarba A, Castellano $\mathrm{M}$, et al. The role of imaging in Graves> disease. Euro $\mathrm{J}$ Rad. 2008;65:99-103.

20. Kumar K, Pasupuleti V, Jayaraman M, Abhyuday V, Rayudu R, Modi K. Role of thyroid Doppler in differerntial diagnosis of thyrotoxicosis. Endocrin Pract. 2009;15:6-9.

Cite this article as: Shirah $\mathrm{BH}$, Shirah HA. Value of total thyroidectomy for Graves' disease in eliminating the risk of recurrence and malignancy: Retrospective database analysis of 574 Saudi Arabian patients in 10 years with 2 years follow up. Int J Otorhinolaryngol Head Neck Surg 2016;2:6-13. 